\title{
Prospects for the classification of mental disorders in
} women

\author{
Anita Riecher-Rössler
}

Psychiatric Outpatient Department, University Hospital, Petersgraben 4, CH-4031 Basel, Switzerland, Tel. +4161265 51 14, Fax +416126545 99, E-Mail: ariecher@uhbs.ch 


\section{Abstract}

Many mental disorders show marked gender differences as regards prevalence, symptomatology, risk factors or course. Other disorders do per definition only occur in women - e.g. premenstrual dysphoric disorder (PMDD) - or are markedly influenced by female specific factors such as hormonal changes over the life cycle or during reproductive processes.

Current classification systems have tried to take into account these gender aspects, but some problems will certainly have to be discussed again with the next revisions of the ICD and DSM.

As regards gender differences in prevalence and symptomatology questions of gender bias in diagnostic instruments and diagnostic criteria will have to be readdressed. New findings from unselected epidemiological samples, which were analysed by gender, will have to be taken into account as well as new findings from research into gender specific personality traits, which can influence the symptomatology of mental disorders. Decisions will have to be taken whether to revise existing diagnostic criteria and provide alternative diagnostic thresholds for men and women or even to develop alternative criteria sets in certain disorders, or rather to enhance the gender neutrality of criteria.

A further question to be addressed will be that of gender specific diagnoses versus diagnostic specifiers. 
In the whole discussion two main aims of classification should be given priority:

a) the research aim of identifying genuine entities with a common aetiology, which means we should be able to identify specific diagnostic entities with descriptive, construct and predictive validity quite independently of the influences of gender - and b) the clinical aim to improve treatment and care for men and women, which often means to offer gender-specific approaches.

Key words: women, gender, psychiatric classification, perimenstruum, postpartum, menopause 
Current classification of mental disorders is mainly based on the World Health Organization (WHO) International Classification of Diseases 10th ed. (ICD 10, (66)) or on the American Psychiatric Association (APA) Diagnostic and Statistical Manual of Mental Disorders, DSM IV (1). Several structured diagnostic interviews have been developed in order to arrive at diagnostic entities defined according to these classifications, including the SCID (Structured Clinical Interview for DSM IV, (51)) and the Composite International Diagnostic Interview - CIDI (64) or e.g. the Present State Examination (PSE, (61)) for ICD.

Both diagnostic systems as well as the corresponding instruments do, however, hardly take into account gender specific aspects, although there is no doubt that sex with its biological and gender with its psychosocial correlates do strongly influence mental well-being as well as psychiatric disorders and diagnoses. Thus many mental disorders show marked gender differences as regards prevalence, symptomatology, risk factors or course. Other disorders do per definition only occur in one gender or are markedly influenced by gender-specific or gender-associated factors.

The following questions will therefore have to be discussed:

- Do we need a gender specific or at least gender sensitive classification?

And if so, how should it look like?

And as these questions can only be answered within a broader context, the question to be asked beforehand will be

-Why do we need classification - what are the main purposes? 
As research has so far mainly been conducted on women, this article will concentrate on them. Similar arguments will, however, have to be discussed for men as well.

\section{WHY DO WE NEED CLASSIFICATION?}

There are many reasons for classifying psychiatric disorders, the main reasons being

- for research, i. e. to detect „true entities“ with a specific common aetiology,

- for clinical reasons, i. e. to improve prediction, treatment and prevention of disorders.

As regards the research aim, it has to be stated that in psychiatry we still have many syndromes with quite unclear aetiology. And as long as we do not know the underlying causes of disorders we try to identify „true“ or „valid“ entities, i. e. disorders with a common underlying aetiology, by identifying specific diagnostic entities. Robins and Guze 1970 (47) as well as Spitzer and Williams 1985 (52) have described how to do this, namely to identify disorders as „valid“ entities, if they show the same symptomatology (descriptive validity), the same risk factors (construct validity) and the same course (predictive validity) (52). Unfortunately, our current diagnostic systems are largely descriptive - that is, based on the clinical presentation of mental disorders rather than their underlying cause. However, with increasing knowledge about the aetiology and pathophysiology, a shift of psychiatric diagnosis, to a more aetiology-oriented approach, can be hoped for. 


\section{DO WE NEED A GENDER SPECIFIC/ SENSITIVE CLASSIFICATION?}

Based on the above named two lines of arguments it shall in the following be delineated why we probably need a gender specific or rather a gender sensitive classification - for research as well as for clinical purposes.

\subsection{Gender sensitive classification for research purposes}

For research purposes we need a gender specific or at least gender sensitive classification in order to control for gender/sex as a "confounding" factor. That is, if we want to identify true entities with specific aetiologies, symptomatologies and courses, we always have to control for gender as an influencing factor which could distort the clinical apprearance of the disorder.

We also know from other areas of medicine, that the same disorder can express itself differently in the two genders. Thus, for example, Blum et al. (9) could show significant gender differences in the clinical presentation of angina pectoris. While men with angina pectoris as compared to women more often complained of chest pain, women more often complained of dyspnoea and gastrointestinal symptoms. Thus, if cardiologists would not have the ECG and other parameters for the differential diagnosis of angina pectoris they would diagnose different syndromes in men and women, i. e. probably more often gastrointestinal disorders in women. 
In psychiatry we unfortunately often do not have such objective parameters as the ECG and often more or less have to rely on symptomatology. If we then do not account for the different symptom presentation of men and women we might sometimes misdiagnose a disorder. Examples for this will be given in the following.

\subsubsection{Explaining gender differences in prevalence rates}

There are many psychiatric disorders which are diagnosed more often in women than in men, e.g. all forms of depression (apart from bipolar depressions), anxiety disorders, eating disorders, somatization disorders or borderline personality. Other disorders are diagnosed more often in men, such as drug and alcohol abuse or antisocial personality (for review see (44)). Unfortunately we do, however, not know, if these gender differences in prevalence are diagnostic artefacts - e. g. due to different symptom presentations in men and women - or if they reflect true differences.

Gender differences in prevalence rates

Table 1 shows the lifetime prevalence of mental disorders in men and women and the respective sex ratios found in some major epidemiological studies using the DSM-III-R or the DSM IV. In the United States 8098 persons, aged 15-54, were investigated within the National Comorbidity Survey (24), in the Netherlands 7076 persons, aged 18-64 within 
the NEMESIS Study (8). In Germany 3021 young people, aged 14-24 were investigated in the Munich study ('Münchner Jugendstudie' (63)) and 4075 people, aged 18-64 in the Luebeck Tacos Study (33).

Table 1 about here

All these studies show a strong preponderance of mood disorders in women with double the lifetime prevalence as compared to men. Also for anxiety disorders the sex ratio women to men is about $2: 1$, for eating disorders even 3,5:1-6,5:1.

Disorders due to alcohol on the other hand show a sex ratio of $0,2: 1-0,5: 1$ and substance abuse disorders a sex ratio of $0,5: 1-0,7: 1$.

Are the gender differences in prevalence artifactual or genuine?

It has often been argued that gender differences in prevalence do not reflect real gender differences, but are rather due to methodological and other research artefacts. However, all the above named studies used a very sound methodology. First of all they were conducted on representative samples of the general population. This means that the results cannot be due to a patient selection, e.g. due to the well known fact that women more often and more regularly seek help then men $(40 ; 42)$. 
Furthermore they were conducted by well-trained interviewers using standardized questionnaires and well-established diagnostic criteria. The results therefore seem to be quite reliable.

Nevertheless, it could well be that even these studies suffer from gender specific biases, e.g. of questionnaires and interviewing techniques, of self reporting, of interpreting the patient information, of applying diagnostic criteria or attributing diagnostic labels.

Example depression

Thus, for example regarding depression, it has been shown, that women remember and report depressive symptoms significantly more often then men $(2 ; 59)$. Women with depression also seem to suffer from more anxious symptoms $(25 ; 48)$. So if the disorder's definition requires more symptoms, women are more likely to get the diagnosis (4). Furthermore women with major depression show a tendency to report greater illness severity and functional impairment, a difference which is more pronounced in self reports as compared to observer-measures $(25 ; 48)$. These findings have also been questioned as reflecting women's greater willingness to report problematic symptoms (68). They also present with different symptoms as compared to men - e.g. more often with "atypical" depression with hypersomnia or weight gain (3) or with a clinical picture of so called "postpartum depression" or "perimenopausal depression". 
Also "female personality traits" could influence the symptom presentation of women. Thus, women on average have been shown to express emotions more intensely (for review see (26) and verbalize emotions more readily (meta-analysis by (17)) Also women as compared to men on average seem to suffer from lower self-esteem (19) and tend to feel guilty more readily (5). They also seem to be more relationship oriented (16) and more strongly dependent on feedback (46). All these factors could contribute to a different presentation of women in the interview situation as compared to men.

Finally men and women seem to have different coping behaviours. In this context it has been discussed that depression in men is partly masked by alcohol abuse, which could be a predominantly male coping behaviour (30).

Finally, as regards the assessment of professionals it has been shown that the diagnostic process is strongly influenced by role sterotypes. Thus depression was diagnosed more readily, when a case vignette was presented to doctors as being the case of a woman than when the same case vignette was presented to them as being the case of a man (54). Gender bias has been shown regarding symptom threshold and case definition and also instruments $(2 ; 53 ; 59 ; 69)$.

Potential causes of "genuine" gender differences

The causes of "genuine" gender differences are certainly partly biological, partly psychosocial and cultural and in most cases multifactorial. 
On the biological side we mainly have to consider genetic and hormonal influences which determine brain development as well as brain functioning and mental wellbeing $(32 ; 44 ; 49)$. Thus we for example know that estradiol, the most important female sex hormone, can modulate a number of neurotransmitter systems, which are relevant for our mental well-being, such as the dopaminergic, the serotonergic or the GABAergic one.

On the psychosocial side there are many risk factors which are unequally distributed between the genders. This starts with early developmental gender differences including gender specific upbringing and socialisation of boys and girls, which determine the sex specific role behaviour later on. Other factors which might contribute to the gender differences in prevalence and course of mental disorders are the differences in social status of men and women, the differences in social stress and social support and many other factors. In fact, women's exposure to environmental stressors tends to differ from those of men in the home, partnership and childrearing as well as in the worksetting $(35 ; 40 ; 44 ; 49)$.

Several other explanatory factors have also been proposed to account for sex differences in psychopathology including differential coping styles, sex roles, poverty, educational status, marital status, income, social support, social isolation, childhood adversity, societal change, cultural norms, exposure to stress and reactivity to stressful life experiences, prior comorbidity or personality traits (21). 


\section{Example depression}

Thus for example regarding the higher rate of depression in women it could be argued that girls' upbringing rather tends to encourage learned helplessness $(19 ; 35)$ and lower self-esteem (19), whilst boys' upbringing tends to focus on active coping behaviour (19). Nolen-Hoeksema (1990) (35) has shown that women with conflicts tend to internalize and react with brooding and so-called "ruminating" as well as with feelings of guilt and depression, while men tend to externalize and seek active, partly even aggressive coping behaviours or react with substance abuse or even suicide. Furthermore women often live in strongly dependent relationships without possibilities of taking influence or gaining control, for example in their partnership or in their professional life, factors which also are known risk factors for depression. Finally girls and women are more often victims of repression, violence, physical and/or sexual abuse $(18 ; 20 ; 67)$. Domestic violence is a known risk factor for depressive and anxiety disorders across cultures (for review see (50)).

Women furthermore very often carry a higher burden of multiple chronic stressors by the fact that they often fulfil multiple roles - as mothers, partners, housekeepers, professionals, caretakers for the elderly family members etc. Women are responsible for the relationships in the family and are usually the caretakers not only for the children but also for elderly parents, which can be a major chronic stressor. Childcare, usually the province of women, is regularly found to be associated 
with increased rates of depression (6). In this context some studies have shown that marriage may affect men and women differently (for review see (50)). Generally women seem to be especially burdened by problems of others in their social network, whom they care for, which has been called "cost of caring". Nazroo et al. (1997) (34) also found that depression in women is more often caused by problems regarding children, reproduction and household, wherelse in men it was more often caused by financial problems. But interestingly this was only true in couples who lived in traditional role stereotypes, not in couples with role equality.

Especially important in this context seems that women via their multiple roles not only suffer from a general overload of duties, but often also from strong role conflicts as these multiple roles are often competing against each other.

Women often have a lower professional status and thereby get less societal appreciation than men. They often live below the threshold of poverty, especially if they are single mothers and get less social support by their partners and family than men $(28 ; 44)$.

In summary, it can be shown that many factors, which are well-known risk factors of depression, are highly associated with female gender $(27 ; 35 ; 67)$.

\subsubsection{Are there "gender-specific" psychiatric disorders?}

A further question for research is, if there are disorders, which are specific to women such as postpartum, premenstrual or perimenopausal disorders. 


\section{Example "Postpartum Depression"}

There has, for example, been an ongoing debate whether "postpartum depression" is a specific entity. Arguments for this were that it shows a symptomatology and course differing from other forms of depression. Furthermore specific risk factors were discussed.

Postpartum depression is also one of the few examples, where current diagnostic systems have suggested specific possibilities of classification:

ICD-10 (65) suggests to code mental disorders associated with the puerperium according to the presenting psychiatric disorder, i.e. with the usual classification number, while a second code (O 99.3) indicates the association with the puerperium. Or, in exceptional circumstances, ICD-10 also allows a special code, F53, to be used if there is "insufficient information" to classify according to given classification criteria or if "special additional features" are noted (table 2).

Table 2 about here

This latter statement has unfortunately opened the door for too many options with the consequence that classification has become somewhat arbitrary. In fact, F53 is sometimes used merely because symptomatology - such as the content of depressive thoughts - is influenced by the specific situation of motherhood. Furthermore, while F53 should only be used if onset is within 6 weeks after delivery, in fact it has often been also used if onset was earlier 
(preexisting disorder) or later. Furthermore ICD does not state clearly if this time criterion refers to the first onset of a disorder only or also to the onset of an episode of a recurrent disorder. This makes classification according to this category even more problematic. Therefore this should only be a "rest" category for cases which do not fulfil other criteria (i.e. those of a depressive episode).

DSM-IV (1) only offers special classification possibilities for mood disorders. Thus, a "postpartum onset specifier" can be applied to all mood disorders in addition to standard classification.

However, if symptomatology of depression in the postpartum period is analysed more closely it becomes quite clear that symptoms are not principally different from those in other depressive disorders not related to childbearing. Rather childbearing and the postpartum situation seem to have a "pathoplastic" effect, i.e. influence the symptomatology in a certain way $(41 ; 45)$. Thus there has often been described an enhanced emotional lability, similar to that seen in postpartum blues, which might have to do with the drop of oestrogen serum levels after delivery and during lactation. Also having a new baby obviously can influence the cognitive content of depression. Mothers often feel guilty for not being good enough mothers, are preoccupied with, at times, irrational worries about the wellbeing of the infant and many of them will report obsessional thoughts, e.g. of harming their child $(11 ; 23 ; 62)$. Many mothers complain about their inability to have any warm feelings for their new-borns. All in all, symptomatology is influenced by the specific situation of being a mother of a newborn, but not "specific" in a sense, which would justify an own diagnostic entity. 
There has also been some controversy about the question whether the incidence of depression is increased in the postpartum period, which would mean that childbirth and its associated factors act as specific aetiological factors or at least triggers. Most studies, however, find incidence and prevalence rates comparable to that in the nonchildbearing

population (for review see $(41 ; 45)$ ). There might be an enhanced risk of mild depression (38) and possibly also a slightly enhanced incidence of major depression in the first postpartum weeks (15), but thereafter the risk seems to be similar to that of other women of the same age group, who - according to the large epidemiological studies (see above) - have quite a high risk for depression anyway. The one-yearprevalence rate of depression reaching the diagnostic threshold does not seem to be enhanced.

When the diagnostic label "postpartum depression" was introduced, some researchers also hypothesized that this was a specific entity with a specific aetiology. Nowadays, most researchers have abandoned this theory. They rather agree that in the postpartum period, we see on principle the same disorders that can also be seen independently from parturition $(12-14 ; 36)$. There does not seem to be a specific aetiology in the strict sense, rather delivery with its dramatic hormonal and psychosocial changes and burdens of the perinatal situation might act as a specific trigger. There also might be a specific psychoneuroendocrine vulnerability in some of the mothers concerned (for review see $(41 ; 45)$ ). The main risk factor, however, which has been identified, is an individual predisposition. About one third of all women with postpartum had already been suffering from similar 
episodes earlier on, and there is also often a corresponding family history $((39 ; 45 ; 57)$, for review see (41)). Genetic factors thus seem to play an important role and have been shown to explain $25-38 \%$ of the variance of postnatal depression in a twin study $(41 ; 56)$.

A vast amount of other risk factors and predictors of "postpartum depression" have been found in different studies, but have not consistently been replicated (for review see $(10 ; 14 ; 41 ; 45))$. Apart from the individual, partly genetic predisposition, the only additional predictors consistently found were anxiety and depression already during pregnancy, baby blues, stress with childcare or general stress, little social support and marital problems (for metaanalyses see $(7 ; 37 ; 60)$. However, it is not clear to what extent these predictors are of pathogenetic relevance and to what extent they are early signs or consequences of the beginning depression $(43 ; 45)$.

Thus the pathogenetic model for developing postpartum depression seems to correspond to the general vulnerability-stress-model of depression. If a woman is predisposed to depression, normal parturition and normal postpartum changes can trigger the outbreak of the disorder or enhance a pre-existing disease and also influence its symptomatology and course. Giving birth to a child with all its consequences seems to act as a major stressor - not only in the sense of a psychosocially stressful life event, but also in the sense of a biological stressor (for review see $(41 ; 45))$.

The third prerequisite required for a specific entity would be a predictive validity, i.e. a specific course. It has sometimes been reported that postpartum depressions show a 
slightly better course than disorders occurring at other times (58). However, if there are any differences, they are not very marked and could be explained in the framework of the vulnerability-stress-model. Thus, giving birth and adapting to the new mother role are obviously major stressors. If a disorder is provoked by such a massive stressor only, underlying vulnerability for the respective disorder might not be very high. After waning of this stressor, the further course of these disorders might thus be quite mild due to the relatively low underlying vulnerability.

In conclusion, it has to be stated that postpartum depression does not seem to be a valid entity with a specific aetiology, symptomatology or course. Nevertheless the clinical picture of depression can be strongly influenced by parturition and early motherhood. These "pathoplastic" influences of gender and the specific postpartum situation have to be born in mind and controlled for, if one does not want to misdiagnose this as a specific disorder.

\subsection{Gender sensitive classification for clinical purposes}

Also for clinical purposes a gender- or situation-specific additional coding could often be very helpful for improving early diagnosis, treatment, service provision and prevention.

\section{Example Postpartum Depression}

Postpartum Depression is also an ideal example for illustrating this, as mothers with a depression in the postpartum period show very specific needs regarding all these areas. 
Thus, diagnosis and treatment of depressive disorders in the postpartum time are often especially seriously delayed (for review see $(41 ; 45))$ as feelings of shame and many fears prevent mothers from seeking help. Furthermore, they often do not realize that they suffer from a disease, but rather feel that they fail as a mother. $A$ lack of specific, low-threshold treatment offers and facilities further contributes to the treatment delay (31).

Specific therapies would have to be offered including psycho-education, counselling and practical advice for the mother and her family. The specific situation also needs specific psychotherapeutic approaches taking into account the role changes of the woman, her relationship with the infant and the partner etc. $(22 ; 45 ; 55)$. The early mother-infant bonding is often severely disturbed, as the mothers concerned often have difficulties in making emotional contact with their infants (29). Thus, a good mother-infant bonding and relationship has to be a main concern from the very start and the mothers should not be separated from their infants for longer periods of time (14). If hospitalization is needed, this should be provided on a mother baby unit. Also domiciliary assessment, home treatment, day hospital and day center care, motherhood classes or playgroups for parents with their children are needed. And finally, women in the peripartum period have a special need to be cared for by multidisciplinary teams including not only psychiatrists and psychologists, but also gynaecologists/obstetricians, paediatricians, midwifes, social workers, and sometimes also lawyers for medico-legal advice or professionals from child protection agencies. 


\section{CONCLUSIONS}

In conclusion a gender sensitive diagnosis could open a window to a better understanding of mental illness and also many chances for improving clinical treatment and care for men and women.

Psychiatric research during the last decades has brought an enormous increase of empirical knowledge about pathogenetic and aetiological factors. Hopefully, this will also improve our diagnostic possibilities in the future. Thus it is hoped that in the diagnostic process a paradigm shift to aetiological considerations will (re-)occur, i. e. that we will be able to develop a new diagnostic system not so much constrained by the limitations of our current categorical descriptive approach anymore.

For identifying "genuine" entities we, however, have still quite a long way to go. One of the ways is, to identify specific diagnostic entities with descriptive, construct and predictive validity quite independently of "confounding" factors. One of the strongest of such "confounding" factors certainly is gender. Gender is not only associated with specific risk factors, but can also influence psychopathology and the course of a disease.

However, in order to control for gender and gender associated factors first of all we have to establish a better empirical knowledge about the influences of gender. In order to do so, new gender focused studies are warranted as well as gender components in all major future studies and secondary analyses of existing data sets. Unselected epidemiological 
samples will have to be analyzed regarding gender differences and it has to be taken great care regarding the gender sensitivity of the methodology of these studies. Thus it will have to be discussed, in which cases gender sensitive instruments should be used and how exactly gender sensitive instruments can be developed. Interviewers should be trained in gender sensitivity. This could for example mean that they challenge men more than women to report on their emotional problems.

It also will have to be analysed very carefully in which cases different diagnostic thresholds for men and women are warranted. Thus, for example, somatisation disorder is being diagnosed in women more often than in men according to DSM IV, possibly because female specific symptoms such as irregular menses, excessive menstrual bleeding and vomiting (without pregnancy) are included as examples of symptoms and are probably not strongly enough counterbalanced by male specific examples such as erectile or ejaculatory dysfunctions. A major problem of gender specific thresholds for diagnoses, however, is how to fix the thresholds. Should the thresholds aim at an equal prevalence for males and females or should they rather allow for different prevalences in the two genders? One of the solutions for this problem might be, to code the "core" syndrome, which is the same in both sexes, and use gender and its associated factors as specifiers.

Specifiers could also be used regarding specific situations like the peripartum or the perimenopause, which would be especially helpful for clinical purposes. Looking for example at depression in the postpartum, a solution for the problem could be, not to diagnose a specific "postpartum depression" but rather to code the depressive disorder according to classical diagnostic criteria and use an additional code/specifier "in the postpartum period". 
Taken together gender has undoubtedly got a major impact on mental disorders, but it is very difficult to take this into account in our diagnostic systems. Specifically, it is very difficult to decide to what extent gender neutral diagnostic criteria should be used as opposed to gender specific criteria. Both approaches have got advantages and disadvantages. The solution might differ for different diagnoses. In any case we need a very good knowledge and description of gender differences in our diagnostic guidelines (DSM V, ICD 11) and training of clinicians in gender sensitivity. In some diagnoses we will have to use gender related modifiers or specifiers, in some cases also gender specific thresholds for diagnoses or even gender specific diagnostic criteria. And in single selected cases, such as erectile disorder or vaginism, gender specific disorders will have to be diagnosed.

Finally, in the absence of independent objective gold standards for the validity of diagnoses more research is certainly needed. Studies should compare across men and women the relationship of criteria sets to external validators such as the risk factors, the treatment responsivity or the course of the disease. Such research could not only be helpful to detect gender-specific pathogenetic factors and new treatment approaches, but also contribute in general to a better understanding of mental illness in both genders. 


\section{Reference List}

(1) American Psychiatric Association. Diagnostic and statistical manual of mental disorders (4th edition DSM-IV). Washington DC: American Psychiatric Press; 1994.

(2) Angst J, Dobler-Mikola A. Do the diagnostic criteria determine the sex ratio in depression? J Affect Disord 1984 Dec; 7(3-4): 189-98

(3) Angst J, Gamma A. Gender differences in depression: The impact of soft bipolarity, atypical features, severity, impairment and age (The menopause). Abstract in World Psychiatry 2003; 2(S1): 12

(4) Angst J, Gamma A, Gastpar M, Lepine JP, Mendlewicz J, Tylee A. Gender differences in depression. Epidemiological findings from the European DEPRES I and II studies. Eur Arch Psychiatry Clin Neurosci 2002 Oct; 252(5): 201-9

(5) Baumeister RF, Stillwell AM, Heatherton TF. Guilt: an interpersonal approach 1.

Psychol Bull 1994 Mar; 115(2): 243-67

(6) Bebbington PE. Psychosocial causes of depression. J Gend Specif Med 1999 Nov; 2(6): 52-60

(7) Beck CT. Meta-analysis of predictors of postpartum depression. Nursing Research 1996; 45(5): 297-303

(8) Bijl RV, Ravelli A, van ZG. Prevalence of psychiatric disorder in the general population: results of The Netherlands Mental Health Survey and Incidence Study (NEMESIS). Soc Psychiatry Psychiatr Epidemiol 1998 Dec; 33(12): 58795

(9) Blum M, Slade M, Boden D, Cabin H, Caulin-Glaser T. Examination of gender bias in the evaluation and treatment of angina pectoris by cardiologists. Am J Cardiol 2004 Mar 15; 93(6): 765-7

(10) Boyce PM. Risk factors for postnatal depression: a review and risk factors in Australian populations. Arch Women Ment Health 2003 Aug; 6 Suppl 2: S43S50

(11) Brockington I. Motherhood and mental health. Oxford, New York, Tokyo: Oxford University Press; 1996.

(12) Brockington I. Diagnosis and management of post-partum disorders: a review. World Psychiatry 2004; 3(2): 303-10

(13) Brockington I, Winokur G, Dean C. Peurperal psychosis. In: Brockington I, Kumar C, editors. Motherhood and Mental Illness. New York: Grune and Stratton; 1982. p. 37-70. 
(14) Brockington I. Postpartum psychiatric disorders. Lancet 2004 Jan 24; 363(9405): 303-10

(15) Cox JL, Murray D, Chapman G. A controlled study of the onset, duration and prevalence of postnatal depression. Br J Psychiatry 1993 Jul; 163: 27-31

(16) Cross SE, Madson L. Models of the self: self-construals and gender 4. Psychol Bull 1997 Jul; 122(1): 5-37

(17) Dindia K, Allen M. Sex differences in self-disclosure: a meta-analysis 1. Psychol Bull 1992 Jul; 112(1): 106-24

(18) Edwards VJ, Holden GW, Felitti VJ, Anda RF. Relationship between multiple forms of childhood maltreatment and adult mental health in community respondents: results from the adverse childhood experiences study. Am J Psychiatry 2003 Aug; 160(8): 1453-60

(19) Feingold A. Gender differences in personality: a meta-analysis. Psychological Bulletin 1994; 116: 429-56

(20) Garcia-Moreno C, Jansen HA, Ellsberg M, Heise L, Watts CH. Prevalence of intimate partner violence: findings from the WHO multi-country study on women's health and domestic violence. Lancet 2006 Oct 7; 368(9543): 1260-9

(21) Grant BF, Weissman MM. Gender and the prevalence of psychiatric disorders. In: Narrow WE, First MB, Sirovatka PJ, Regier DA, editors. Age and Gender Considerations in Psychiatric Diagnosis - A Research Agenda for DSM-V. Arlington Virginia: American Psychiatric Association; 2007. p. 31-45.

(22) Hofecker-Fallahpoor M, Zinkernagel Ch, Frisch U, Neuhofer C, Stieglitz RD, Riecher-Rössler A. Was Mütter depressiv macht... und wodurch sie wieder Zuversicht gewinnen. Ein Therapiehandbuch. Bern: Huber; 2005.

(23) Jennings KD, Ross S, Popper S, Elmore M. Thoughts of harming infants in depressed and nondepressed mothers. J Affect Disord 1999 Jul; 54(1-2): 21-8

(24) Kessler RC, McGonagle KA, Zhao S, Nelson CB, Hughes M, Eshleman S, et al. Lifetime and 12-month prevalence of DSM-III-R psychiatric disorders in the United States. Results from the National Comorbidity Survey. Arch Gen Psychiatry 1994 Jan; 51(1): 8-19

(25) Kornstein SG, Schatzberg AF, Thase ME, Yonkers KA, McCullough JP, Keitner Gl, et al. Gender differences in chronic major and double depression. J Affect Disord 2000 Oct; 60(1): 1-11

(26) Kring AM, Gordon AH. Sex differences in emotion: expression, experience, and physiology 1. J Pers Soc Psychol 1998 Mar; 74(3): 686-703

(27) Kühner C. Affektive Störungen. In: Franke A, Kämmerer A, editors. Klinische Psychologie der Frau - Ein Lehrbuch. Göttingen, Bern, Toronto, Seattle: Hogrefe-Verlag; 2001. p. 165-208. 
(28) Kühner C. Gender differences in unipolar depression: an update of epidemiological findings and possible explanations. Acta Psychiatr Scand 2003; 108: 163-74

(29) Kumar RC. "Anybody's child": severe disorders of mother-to-infant bonding. British Journal of Psychiatry 1997; 171: 175-81

(30) Levav I, Kohn R, Golding JM, Weissman MM. Vulnerability of Jews to affective disorders. Am J Psychiatry 1997 Jul; 154(7): 941-7

(31) Macarthur C. What does postnatal care do for women's health? Lancet 1999 Jan 30; 353(9150): 343-4

(32) Marsh L, Casper RC. Gender differences in brain morphology and in psychiatric disorders. In: Casper RC, editor. Women's health: hormones, emotions and behaviour. Cambrigde, New York, Melbourne: Cambridge University Press; 1998. p. 53-82.

(33) Meyer C, Rumpf HJ, Hapke U, Dilling H, John U. [Lifetime prevalence of mental disorders in general adult population. Results of TACOS study]. Nervenarzt 2000 Jul; 71(7): 535-42

(34) Nazroo JY, Edwards AC, Brown GW. Gender differences in the onset of depression following a shared life event: a study of couples. Psychol Med 1997; 27: 9-19

(35) Nolen-Hoeksema S. Sex differences in depression. Stanford: Stanford University Press; 1990.

(36) O'Hara MW. Post-partum "blues", depression, and psychosis: a review. J psychosom Obstet Gynaecol 1987; 7: 205-27

(37) O'Hara MW, Swain AM. Rates and risk of postpartum depression - a metaanalysis. International Review of Psychiatry 1996; (8): 37-54

(38) O'Hara MW, Zekoski EM, Philipps LH, Wright EJ. Controlled prospective study of postpartum mood disorders: comparison of childbearing and nonchildbearing women. J Abnorm Psychol 1990 Feb; 99(1): 3-15

(39) Paykel ES, Emms EM, Fletcher J, Rassaby ES. Life events and social support in puerperal depression. Br J Psychiatry 1980 Apr; 136: 339-46

(40) Peterson B, Kastrup M. Gender and mental health. In: Jablensky A, editor. Epidemiological psychiatry. London, Philadelphia, Sydney, Tokyo, Toronto: Baillère Tindall; 1995. p. 329-48.

(41) Riecher-Roessler A, Rohde A. Diagnostic Classification of Perinatal Mood Disorders. In: Riecher-Roessler A, Steiner M, editors. Perinatal Stress, Mood and Anxiety Disorders - From Bench to Bedside. Basel: Karger; 2005. p. 6-27.

(42) Riecher-Rössler A. Warum brauchen wir eine geschlechtersensible Psychiatrie und Psychotherapie. In: Rohde A, Riecher-Rössler A, editors. 
Psychische Erkrankungen bei Frauen - Psychiatrie und Psychosomatik in der Gynäkologie. Regensburg: S. Roderer Verlag; 2001. p. 41-54.

(43) Riecher-Rössler A, Hofecker Fallahpour M. Die Depression in der Postpartalzeit - Eine diagnostische und therapeutische Herausforderung. Schweizer Archiv für Neurologie und Psychiatrie 2003; 154(3): 106-54

(44) Riecher-Rössler A, Bitzer J. Epidemiologie psychischer Störungen bei Frauen. In: Riecher-Rössler A, Bitzer J, editors. Frauengesundheit. Ein Leitfaden für die ärztliche und psychotherapeutische Praxis. München, Jena: Elsevier Urban \& Fischer; 2005. p. 21-9.

(45) Riecher-Rössler A, Hofecker FM. Postpartum depression: do we still need this diagnostic term? Acta Psychiatr Scand Suppl 2003; (418): 51-6

(46) Roberts TA, Nolen-Hoeksema S. Sex differences in reactions to feedback. Sex Roles 1989; 21(11-12): 725-47

(47) Robins E, Guze SB. Establishment of diagnostic validity in psychiatric illness: its application to schizophrenia. Am J Psychiatry 1970 Jan; 126(7): 983-7

(48) Scheibe S, Preuschhof C, Cristi C, Bagby RM. Are there gender differences in major depression and its response to antidepressants? J Affect Disord 2003 Aug; 75(3): 223-35

(49) Seeman MV. Gender and psychopathology. Washington DC, London: American Psychiatric Press; 1995.

(50) Shear K, Halmi KA, Widiger TA, Boyce C. Sociocultural factors and gender. In: Narrow WE, First MB, Sirovatka PJ, Regier DA, editors. Age and Gender Considerations in Psychiatric Diagnosis - A Research Agenda for DSM-V. Arlington Virginia: American Psychiatric Association; 2007. p. 65-79.

(51) Spitzer,RL, M Gibbon, Williams J. Structured Clinical Interview for Axis I DSMIV disorders (SCID). Washington DC: American Psychiatric Association Press; 1995

(52) Spitzer RL, Williams JBV. Classification in psychiatry. In: Kaplan HI, Freedman AM, Sadock BJ, editors. Comprehensive textbook of psychiatry. Baltimore: Williams and Wilkins; 1985. p. 591-613.

(53) Stommel M, Given BA, Given CW, Kalaian HA, Schulz R, McCorkle R. Gender bias in the measurement properties of the Center for Epidemiologic Studies Depression Scale (CES-D). Psychiatry Res 1993 Dec; 49(3): 239-50

(54) Stoppe G, Sandholzer H, Huppertz C, Duwe H, Staedt J. Gender differences in the recognition of depression in old age. Maturitas 1999 Aug 16; 32(3): 20512

(55) Stuart S, O'Hara MW. Treatment of postpartum depression with interpersonal psychotherapy. Arch Gen Psychiatry 1995 Jan; 52(1): 75-6 
(56) Treloar SA, Martin NG, Bucholz KK, Madden PA, Heath AC. Genetic influences on post-natal depressive symptoms: findings from an Australian twin sample. Psychol Med 1999 May; 29(3): 645-54

(57) Watson JP, Elliott SA, Rugg AJ, Brough DI. Psychiatric disorder in pregnancy and the first postnatal year. Br J Psychiatry 1984 May; 144: 453-62

(58) Whiffen VE, Gotlib IH. Comparison of postpartum and nonpostpartum depression: clinical presentation, psychiatric history, and psychosocial functioning. J Consult Clin Psychol 1993 Jun; 61(3): 485-94

(59) Wilhelm K, Parker G. Sex differences in lifetime depression rates: fact or artefact? Psychol Med 1994 Feb; 24(1): 97-111

(60) Wilson LM, Reid AJ, Midmer DK, Biringer A, Carroll JC, Stewart DE. Antenatal psychosocial risk factors associated with adverse postpartum family outcomes. CMAJ 1996; 154(6): 785-99

(61) Wing,JK, J E Cooper, N Sartorius. Measurement and Classification of Psychiatric Symptoms: An Introduction Manual for the PSE and CategoProgram. London: Cambridge University Press; 1974.

(62) Wisner KL, Peindl KS, Gigliotti T, Hanusa BH. Obsessions and compulsions in women with postpartum depression. J Clin Psychiatry 1999 Mar; 60(3): 176-80

(63) Wittchen HU, Nelson CB, Lachner G. Prevalence of mental disorders and psychosocial impairments in adolescents and young adults. Psychol Med 1998 Jan; 28(1): 109-26

(64) World Health Organisation. Composite International Diagnostic Interview (CIDI) Version 1.0. Geneva: World Health Organization; 1990.

(65) World Health Organisation. The ICD-10 Classification of mental and behavioral disorders. Geneva: World Health Organisation; 1992.

(66) World Health Organisation. World Health Organization: The ICD-10 Classification of Diseases ICD-10 Chapter F. Geneva: World Health Organization; 1992.

(67) World Health Organization. Women's mental health: an evidence based review. Genf: World Health Organization; 2000.

(68) Yonkers KA, Narrow WE, Halmi KA. Clinical Validators of Diagnoses Sympton Expression, Course, and Treatment. In: Narrow WE, First MB, Sirovatka PJ, Regier DA, editors. Age and gender considerations in psychiatric diagnosis - A research agenda for DSM-V. Arlington, Virginia: American Psychiatric Association; 2007. p. 113-25.

(69) Young EA, Midgley AR, Carlson NE, Brown MB. Alteration in the hypothalamic-pituitary-ovarian axis in depressed women. Arch Gen Psychiatry 2000 Dec; 57(12): 1157-62 
Table 1

Lifetime Prevalence of Mental Disorders in Women and Men and Sex Ratios

a) Epidemiological Studies based on CIDI/DSM-III-R ${ }^{1}$

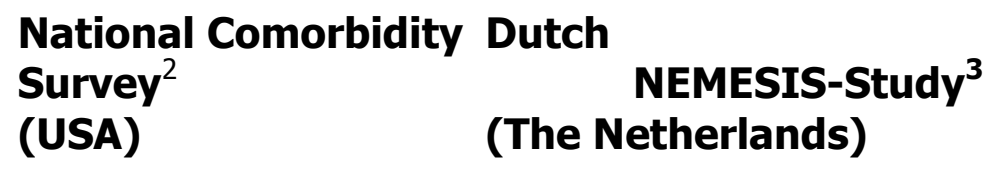

$\mathrm{n}=8098 ; 15-54$ yrs. $\mathrm{n}=7076 ; 18-64$ yrs.

rate* rate* ratio rate* rate* ratio

women men $F: M$ women men $F: M$

\begin{tabular}{|c|c|c|c|c|c|c|}
\hline $\begin{array}{l}\text { mood disorders } \\
\text { major depression } \\
\text { dysthymia }\end{array}$ & $\begin{array}{l}23.9 \\
21.3 \\
8.0\end{array}$ & $\begin{array}{l}14.7 \\
12.7 \\
4.8\end{array}$ & $\begin{array}{l}1.6 \\
1.7 \\
1.7\end{array}$ & $\begin{array}{l}24.5 \\
20.1 \\
8.9\end{array}$ & $\begin{array}{l}13.6 \\
10.9 \\
3.8\end{array}$ & $\begin{array}{l}1.8 \\
1.8 \\
2.3\end{array}$ \\
\hline $\begin{array}{l}\text { anxiety disorders } \\
\text { general anxiety dis. } \\
\text { panic disorders } \\
\text { social phobia } \\
\text { agoraphobia } \\
\text { obsess.-comp. dis. }\end{array}$ & $\begin{array}{l}30.5 \\
6.6 \\
5.0 \\
15.5 \\
7.0 \\
-\end{array}$ & $\begin{array}{l}19.2 \\
3.6 \\
2.0 \\
11.1 \\
3.5 \\
-\end{array}$ & $\begin{array}{l}1.6 \\
1.8 \\
2.5 \\
1.4 \\
2.0 \\
-\end{array}$ & $\begin{array}{l}25.0 \\
2.9 \\
5.7 \\
9.7 \\
4.9 \\
0.8\end{array}$ & $\begin{array}{l}13.8 \\
1.6 \\
1.9 \\
5.9 \\
1.9 \\
0.9\end{array}$ & $\begin{array}{l}1.8 \\
1.8 \\
3.0 \\
1.6 \\
2.6 \\
0.9\end{array}$ \\
\hline eating disorders & - & - & - & 1.3 & 0.2 & 6.5 \\
\hline $\begin{array}{l}\text { alcohol abuse/ } \\
\text { dependency }\end{array}$ & 14.6 & 32.6 & 0.5 & 5.8 & 28.3 & 0.2 \\
\hline $\begin{array}{l}\text { drug abuse/ } \\
\text { dependency }\end{array}$ & 9.4 & 14.6 & 0.6 & 2.6 & 4.1 & 0.7 \\
\hline antisocial pers. & 1.2 & 5.8 & 0.2 & - & - & - \\
\hline schizophrenia & 0.8 & 0.6 & 1.3 & 0.3 & 0.4 & 0.8 \\
\hline total rate & 47.3 & 48.7 & 1.0 & 39.9 & 42.5 & 0.9 \\
\hline
\end{tabular}




\section{Table 1}

Lifetime Prevalence of Mental Disorders in Women and Men and Sex Ratios

b) Epidemiological Studies based on CIDI/DSM-IV ${ }^{4}$

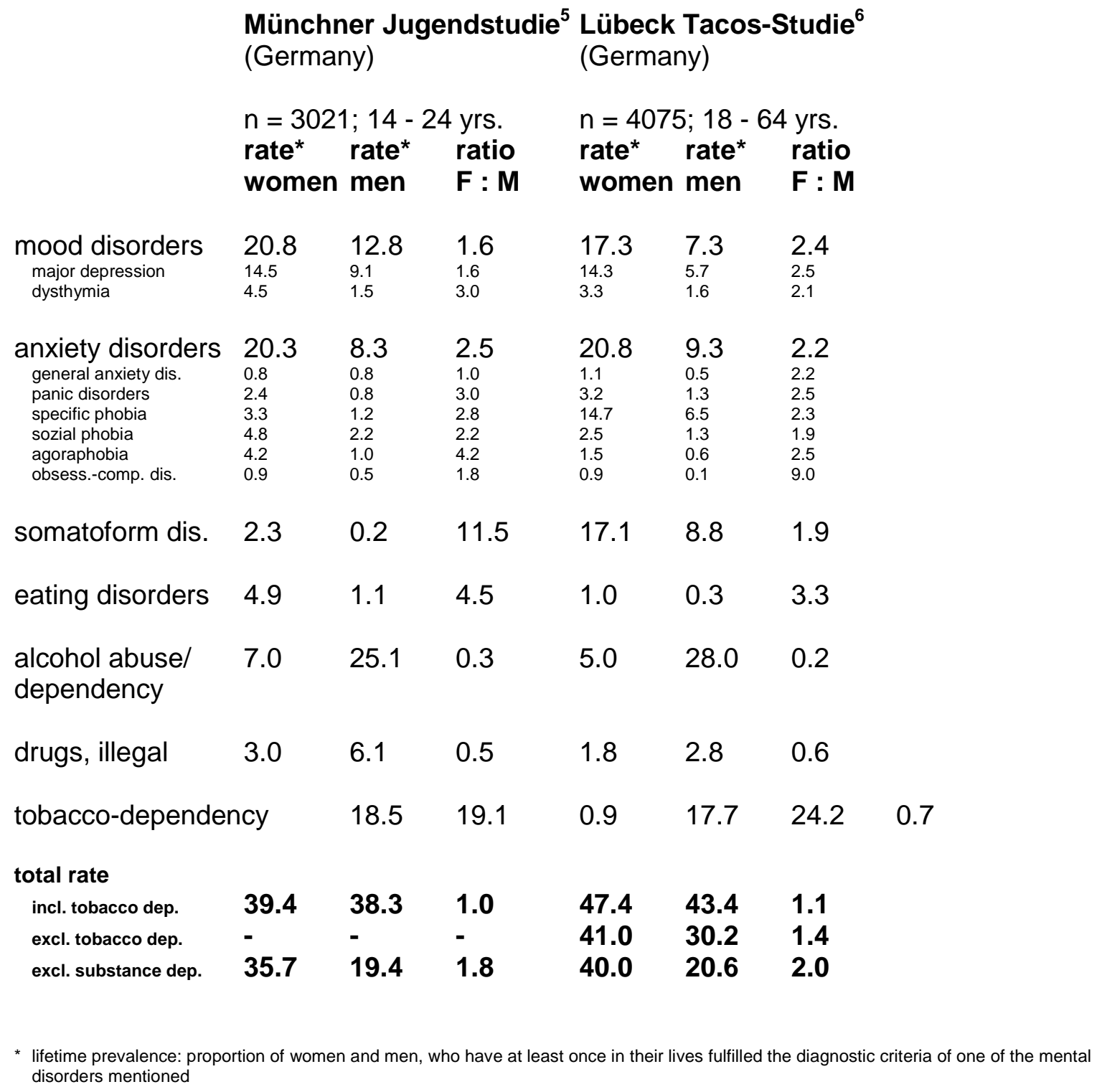

Table 2 


\section{ICD-10 classification of postpartum depression ${ }^{7}$}

Code:

1. Presenting psychiatric disorder +

2. $\quad 099.3$ for "Mental disorder complicating puerperium"

Only use exceptionally:

F53 Mental and behavioural disorders associated with the puerperium, not elsewhere classified

- commencing within 6 weeks of delivery

- not meeting the criteria for disorders classified elsewhere

. because of insufficient information or

. because of special additional features

F53.0 Postpartum depression

F53.1 Postpartum psychosis

F53.8 Other disorders

F53.9 Unspecified 